\title{
Intact Learning of New Relations in Amnesia as Achieved through Unitization
}

\author{
Jennifer D. Ryan, ${ }^{1,2,3}$ Sandra N. Moses, ${ }^{1,4,5}$ Morgan Barense, ${ }^{1,2}$ and R. Shayna Rosenbaum ${ }^{1,6}$ \\ ${ }^{1}$ Rotman Research Institute, Baycrest, Toronto, Ontario M6A 2E1, Canada, Departments of ${ }^{2}$ Psychology, ${ }^{3}$ Psychiatry, and ${ }^{4}$ Medical Imaging, The University \\ of Toronto, Toronto, Ontario M5S 1A1, Canada, ${ }^{5}$ Departments of Diagnostic Imaging, and Neurosciences \& Mental Health, The Hospital for Sick Children, \\ Toronto, Ontario M5G 1X8, Canada, and 'Department of Psychology, York University, Toronto, Ontario M3J 1P3, Canada
}

Hippocampal amnesia is defined by deficits in the binding of relations among items-a deficit captured by the transverse patterning (TP) task. Unitization is a processing mechanism that may allow amnesic patients to compensate for relational memory deficits. Amnesic patient D.A. demonstrated intact TP, and performance was maintained 1 month following training. Successful acquisition of relations occurred only when D.A. fused or integrated objects into a unified representation. D.A. did not acquire relations when he did not generate such integrated scenarios, and acquisition of relations was slowed when integration had to occur for novel stimuli. Amnesic patients K.C. and R.F.R. were tested to provide comparative data; K.C. and R.F.R. did not benefit from unitization, perhaps due to additional cortical damage. We propose that unitization requires visual imagery of multiple items that are fused/integrated; through the benefit of extended on-line maintenance, this fused representation is anchored to existing representations in semantic memory.

\section{Introduction}

Hippocampal amnesia is punctuated by deficits in acquiring and maintaining lasting representations regarding relations among distinct items (Cohen and Eichenbaum, 1993; Eichenbaum and Cohen, 2001; Moses and Ryan, 2006) (i.e., relational binding). The transverse patterning (TP) task has often been used to examine the integrity of relational binding and hippocampal function. TP is akin to the game of "rock-paper-scissors," in which the reward value of each stimulus must be evaluated with respect to another (A wins over B, B wins over C, C wins over A). Learning the reward history of the individual items is insufficient as each item is rewarded and unrewarded equally; as such, TP requires that the relations among items be learned (Sutherland and Rudy, 1989; Driscoll et al., 2005). Although numerous studies reveal that hippocampal lesions impair TP performance (Alvarado and Rudy, 1995; Rickard and Grafman, 1998; Reed and Squire, 1999; Driscoll et al., 2003, 2005; Rickard et al., 2006; Moses et al., 2008), several recent studies have demonstrated intact or facilitated TP performance in nonhuman animals with hippocampal (Saksida

\footnotetext{
Received Jan. 14, 2013; revised March 25, 2013; accepted April 22, 2013.

Author contributions: J.D.R., S.N.M., and R.S.R. designed research; J.D.R., S.N.M., M.B., and R.S.R. performed research; J.D.R. and S.N.M. analyzed data; J.D.R., S.N.M., M.B., and R.S.R. wrote the paper.

This work was supported by funding from the Natural Sciences and Engineering Research Council of Canada (NSERC) and the Canada Research Chairs Program awarded to J.D.R. R.S.R. is supported by a Canadian Institutes of Health Research (CIHR) New Investigator Award, an Ontario Ministry of Economic Development and Innovation Early Researcher Award, and an Alfred P. Sloan Foundation Research Fellowship. M.B. is supported by NSERC and CIHR. We acknowledge the patients and their families for their continued involvement in research. We thank Asaf Gilboa for his invaluable discussions on this work, and Melanie 0 streicher for her assistance in data analysis.

This article is freely available online through the J Neurosci Author Open Choice option.

Correspondence should be addressed to Dr. Jennifer D. Ryan, Rotman Research Institute, Baycrest, 3560 Bathurst Street, Toronto, 0N M6A 2E1 Canada. E-mail: jryan@research.baycrest.org.

DOI:10.1523/JNEUROSCI.0169-13.2013

Copyright $\odot 2013$ the authors $\quad 0270-6474 / 13 / 339601-13 \$ 15.00 / 0$
}

et al., 2007) or fornix lesions (Bussey et al., 1998; Brasted et al., 2003) and in humans on other tasks that presumably required relational memory (Goshen-Gottstein et al., 2000; Corkin, 2002; Verfaelllie et al., 2012). Here we report three well studied amnesic cases (patients D.A., K.C., and R.F.R.), all of whom have extensive medial temporal lobe (MTL) damage, including the hippocampus and perirhinal cortex (PRC) bilaterally, have impairments on standard episodic memory tests and limited semantic learning. However, one of these patients, D.A., achieves high performance on TP. The critical question is: what is mediating successful TP in the absence of a functioning hippocampus?

When hippocampal function is impaired, performance may be supported by inflexible stimulus "blends," in which multiple items are fused into a unified representation (Eichenbaum et al., 1994; Cohen et al., 1997; Moses and Ryan, 2006). Unitization allows disparate pieces of information to be combined into a single, higher-order, functional unit and maintained in memory (Tulving and Patterson, 1968; Winograd and Rivers-Bulkeley, 1977; Graf and Schacter, 1989). Under unitization encoding instructions, amnesics have shown increased recognition accuracy for previously studied pairs of items, albeit less than that of controls (Quamme et al., 2007).

This study provides evidence of intact TP performance by amnesic patient D.A. and reveals the spontaneous use of a unitization strategy to compensate for impaired relational binding. We assessed whether D.A. could use experimenterprovided unitization strategies to support performance in novel TP conditions and the extent to which performance was affected by delay. Data from K.C. and R.F.R. are presented for comparison with D.A. and to determine whether their TP performance could benefit from unitization strategies. By considering performance in conjunction with individual differences in neuroanatomical and neuropsychological profiles, this 
Table 1. Neuropsychological profiles of the amnesic cases

\begin{tabular}{|c|c|c|c|}
\hline & D.A. & K.C. & R.F.R. \\
\hline \multicolumn{4}{|l|}{ Intellectual function } \\
\hline WASI (standard score) FSIQ & $117^{a}$ & 99 & 128 \\
\hline VIQ & $121^{a}$ & 99 & - \\
\hline PIQ & $106^{a}$ & 99 & - \\
\hline AM-NART (standard score) & 117 & 102 & - \\
\hline \multicolumn{4}{|l|}{ Language } \\
\hline WAIS-R vocabulary (scaled score) & 12 & 9 & - \\
\hline BNT $(/ 60)$ & 56 & 57 & $55 / 64^{b}$ \\
\hline Semantic fluencyc (scaled score) & 12 & 10 & - \\
\hline \multicolumn{4}{|l|}{ Anterograde memory } \\
\hline WMS-R general memory (standard score) & 74 & 61 & - \\
\hline Verbal memory (standard score) & 74 & 67 & - \\
\hline Visual memory (standard score) & 81 & 69 & - \\
\hline LPI (percentile) & 15th & 5 th & $21 s t-32 n d$ \\
\hline LP II (percentile) & $<1$ st & $<1 s t$ & $<1 s t^{d}$ \\
\hline VRI (percentile) & 19th & 13th & - \\
\hline VR II (percentile) & $<1$ st & $<1 s t$ & - \\
\hline WRMT (/50) words & 21 & 26 & 31 \\
\hline WRMT $(/ 50)$ faces & 25 & 25 & 32 \\
\hline CVLT acquisition (t-score) & 9 & 12 & - \\
\hline Short delay free (z-score) & -4 & -4 & - \\
\hline Long delay free (z-score) & -4 & -4 & - \\
\hline Recognition discrimination (z-score) & -4 & -3 & - \\
\hline ROCF (/36) copy & 35 & 36 & 36 \\
\hline Immediate recall & - & 4 & - \\
\hline Delayed recall & 0 & 0 & 0 \\
\hline \multicolumn{4}{|l|}{ Retrograde memory } \\
\hline AMI Autobiographical (/9) childhood & 7 & 2 & - \\
\hline Early adult life & 6 & 3 & - \\
\hline Recent life & 3 & 1 & - \\
\hline AMI personal semantics (/21) childhood & 17.5 & 16 & - \\
\hline Early adult life & 21 & 13.5 & - \\
\hline Recent life & 16 & 8 & - \\
\hline \multicolumn{4}{|l|}{ Visual perception } \\
\hline Judgment of line orientation (/30) & 26 & 23 & 23 \\
\hline Benton visual discrimination test (percentile) & - & $>95$ th & - \\
\hline Benton facial recognition test (percentile) & - & 2-16th & 88-97th \\
\hline \multicolumn{4}{|l|}{ Executive function } \\
\hline FAS phonemic fluency ${ }^{e}$ (scaled score) & 8 & 6 & - \\
\hline Trail making test, part A (s) & - & 138 & 150 \\
\hline Trail making test, part B (s) & - & 291 & 178 \\
\hline WAIS-R digits (scaled score) & 13 & 12 & 9 \\
\hline WCST Categories (/6) & 6 & 6 & 6 \\
\hline Perseverative responses (z-score) & -0.5 & -0.9 & 1.0 \\
\hline
\end{tabular}

WASI, Wechsler Abbreviated Scale of Intelligence; AM-NART, American National Adult Reading Test; BNT, Boston Naming Test; WMS-R, Wechsler Memory Scale-Revised; LP, Logical Passages; VR, Visual Reproduction; WRMT, Warrington Recognition Memory Test; CVLT, California Verbal Learning Test; ROCF, Rey Osterrieth Complex Figure; AMI, Autobiographical Memory Interview; Venton Visual Discrimination Test; Benton Facial Recognition Test; FAS phonemic fluency; Trail Making Test; WCST, Wisconsin Card Sorting Test; WAIS-R, Wechsler Adult Intelligence Scale-revised; WAIS-III, Wechsler Memory Scale-III.

${ }^{a}$ Number represents standard score on the WAIS-R.

${ }^{b}$ Total score is 64, based on test described in Adlam et al. (2010).

'Score is based on the number of animal names produced in $1 \mathrm{~min}$.

${ }^{d}$ Number represents percentile on the WAIS-III.

${ }^{e} S$ core is based on the total number of words produced for the letters $F$, $A$, and $S$ when given 1 min for each.

work sheds light on the critical factors that determine whether individual amnesic cases may benefit from unitization.

\section{Materials and Methods}

Amnesic patients and control participants

Additional details regarding the cognitive and neurological profiles of the amnesic patients are provided in Tables 1 , and 2 and 3, respectively, as well as in Rosenbaum et al. (2004 patient D.A., 2005, patient K.C.) and Barense et al. (2007; patient R.F.R. is described as MTL case 2). Table 2 indicates substantial bilateral volume loss in the MTL, affecting the hip- pocampus and adjacent cortices in D.A. and K.C. Due to claustrophobia, it was not possible to obtain a research-quality scan for R.F.R. that was suitable for volumetric analyses. However, qualitative visual ratings of a clinical MRI scan that had been validated successfully against volumetric measures also indicated significant bilateral damage to the hippocampus and adjacent cortices (Table 3).

D.A. was 56 years old at the time of initial testing. He is a right-handed man with 17 years of education. He contracted herpes simplex encephalitis in 1993, which resulted in bilateral MTL damage. As outlined in Rosenbaum et al. (2008), D.A.'s lesions encompass nearly his entire right MTL, including the hippocampus and parahippocampal gyrus along its entire extent (perirhinal, entorhinal, and parahippocampal cortices) as well as the right anterior temporal lobe. He has less than one-third remaining of his left hippocampus and entorhinal cortex, and has nearly complete loss of his left perirhinal and parahippocampal cortices. In D.A., disproportionate volume loss within the right hemisphere was found to extend to the following structures outside of the MTL: ventral frontal cortex; anterior cingulate cortex (ACC); anterior and posterior temporal cortex; and occipital cortex. Small lesions were also observed in the right posterior thalamus and the left middle temporal gyrus. In contrast, dorsal frontal, posterior cingulate, and inferior and superior parietal cortices were found to be spared bilaterally.

D.A.'s cognitive function is generally intact other than extensive anterograde amnesia and a temporally graded retrograde amnesia extending $\sim 30$ years for autobiographical events (Rosenbaum et al., 2008). In particular, D.A. shows preserved access to, and use of, information stored within semantic memory, as well as some new learning of semantic information (Westmacott and Moscovitch, 2002). Additionally, D.A. exhibits high average working memory (Rosenbaum et al., 2008), and his visual imagery for objects and spatial location is within the normal range and allows him to recombine known images into novel ones (unpublished data) (for task descriptions and a report of similar performance in K.C., see Rosenbaum et al. (2004)).

K.C. was 56 years of age at the initial time of testing. K.C. is a righthanded man with 16 years of education who suffered a closed head injury, resulting in multifocal and diffuse brain damage that included almost complete bilateral hippocampal damage and less extensive, though still significant, atrophy of his parahippocampal gyrus bilaterally, with the greatest loss in entorhinal cortex (for further details, see Rosenbaum et al., 2005). In K.C., there is damage to other memory-related structures including the following: bilateral septum; caudate and anterior and posterior thalamus; and left mammillary bodies and amygdala. Damage to other extra-MTL regions is largely within the left hemisphere, and includes occipitotemporal structures, from cuneus and through lingual and parahippocampal gyri, and dorsolateral frontal cortex, whereas bilateral ventral frontal, anterior, and posterior cingulate, and lateral temporal cortices are largely intact.

K.C.'s cognitive functioning has been reported as generally intact, save for an extensive anterograde and retrograde amnesia (notably extremely impaired episodic memory, whether tested with recall or recognition) and impairments in future-oriented thinking and imagining (Tulving, 1985; Rosenbaum et al., 2005, 2009). Similar to D.A., K.C. shows spared access and use of information maintained within semantic memory, and some, albeit limited, ability to acquire new semantic information (Tulving et al., 1991; Hayman et al., 1993; Westmacott and Moscovitch, 2001). His visual imagery is within the normal range (Rosenbaum et al., 2004), and his working memory capacity is within normal limits, in the low average to average range.

R.F.R. was 76 years of age at the initial time of testing. R.F.R. is a right-handed man with 12 years of formal education. R.F.R. had sustained bilateral MTL damage following viral encephalitis in 1985 (for description of full etiology, see Warrington and McCarthy, 1988). A detailed analysis of his lesion has been reported previously (Barense et al., 2007; case MTL 2). To summarize, R.F.R. has extensive MTL damage, including bilateral damage to the hippocampus; amygdala; and entorhinal, perirhinal, parahippocampal, and temporopolar cortices (Tables 2, 3). Like K.C., lateral temporal lobe structures are intact, and structures outside the temporal lobe are additionally intact. R.F.R. has extremely impaired episodic memory (both recall and recognition) and mildly im- 
Table 2.Z-scores for medial temporal lobe volumes for D.A. and K.C.

\begin{tabular}{lllllllll}
\hline & Left perirhinal & Left entorhinal & Left PHG & Right perirhinal & Right entorhinal & Right PHG & Left hippocampus & Right hippocampus \\
\hline D.A. & -9.75 & -6.65 & -4 & -7.12 & -6.02 & -3.13 & -4.14 & -5.19 \\
K.C. & -19.1 & & & -4.8 & & & -7.8 & -9.8 \\
\hline
\end{tabular}

Detailed examination of MTL structures in D.A. and K.C. was accomplished using manual tracing on the normalized and coregistered T1-weighted images according to Insausti et al. (1998) for the hippocampus, entorhinal cortex, and perirhinal cortex and according to Callen et al. (2001) for the parahippocampal cortex (a combined estimate of parahippocampal gyrus volume is provided for KC).Z-scores were calculated using mean volumes corrected for head size for four controls demographically matched to D.A. and five controls matched to K.C. (for further details, see Rosenbaum et al., 2005, 2008).

Table 3. Structural MRI scan ratings (with SDs) for R.F.R. and a group of age-matched controls for various brain regions averaged across both hemispheres

\begin{tabular}{|c|c|c|c|c|c|c|c|c|c|}
\hline & Temporo-polar cortex & Amygdala & PHG & MBCS & Perirhinal (LBCS) & MBOS & Anterior hippocampus & Lateral temporal cortex & Posterior hippocampus \\
\hline R.F.R. & $2^{*}$ & $3^{*}$ & $2.5^{*}$ & $2.75^{*}$ & $2.5^{*}$ & $2^{*}$ & $3^{*}$ & 1 & $2.75^{*}$ \\
\hline $\begin{array}{c}\text { Control mean } \\
(n=12)\end{array}$ & $0.313(0.284)$ & $0.375(0.483)$ & $0.188(0.188)$ & $0.521(0.291)$ & $0.271(0.310)$ & $0.333(0.289)$ & $0.458(0.382)$ & $0.458(0.411)$ & $0.271(0.361)$ \\
\hline
\end{tabular}

Structural MRI scan ratings (with SDs) for RFR and a group of age-matched controls for various brain regions (ordered from anterior to posterior location in the brain), averaged across both hemispheres. 0 , No visible damage; 3 ( 4 for anterior hippocampus), complete absence of area; PHG, parahippocampal gyrus (corresponding to entorhinal cortex); MBCS, medial bank of collateral sulcus (corresponding to the transition between entorhinal and perirhinal cortex); LBCS, lateral bank of collateral sulcus (corresponding to perirhinal cortex); MBOS, medial bank of occipitotemporal sulcus (corresponding to the transition between perirhinal and isocortex.

*Significant difference compared with control mean. For further details, see Barense et al. (2007).

paired semantic memory (Barense et al., 2012). His performance on standard neuropsychological tests of visual perception (e.g., Visual Object and Space Perception, Benton Faces) is normal, although his perception of objects with many overlapping features is not (Barense et al., 2005, 2007, 2012). Like D.A. and K.C., he is able to acquire some new semantic information (Dewar et al., 2009), and his digit span and performance on tests of executive function and abstract problem solving are within the normal range.

Healthy adults with no known pathology were recruited from the Rotman Research Institute volunteer pool and participated in exchange for monetary compensation. All participants (patients and controls) gave informed written consent. Research ethics guidelines for the testing of D.A., K.C., and the control participants were obtained through the Rotman Research Institute at Baycrest, which complies with the guidelines set by the Toronto Academic Health Science Council. Research ethics guidelines for the testing of R.F.R. were approved by the Cambridgeshire Local Research Ethics Committee and the Oxfordshire Research Ethics Committee.

\section{Apparatus and stimuli}

Two stimuli were presented using E-prime 1.1 on each trial, and were counterbalanced for presentations on the right and left sides of the screen across trials. Participants responded using keys "p" and "q" on a standard keyboard. A 19 inch monitor was used and was set at $1024 \times 768$ pixel resolution and 24-bit high color. Three stimuli (A-C) were used in each of the six experimental conditions: Rock-Paper-Scissors (RPS), Playing Cards, Geometric Shapes, Abstract Objects, Geometric Shapes-Unitized, and Abstract Objects-Unitized. The conditions varied in the extent to which the objects and the relations among them were known before the experimental session (Fig. 1a). RPS and Playing Cards conditions each contained known objects for which the relations were also known before the experimental session. The RPS stimuli show depictions of the hand game in which rock crushes scissors, scissors cut paper, paper covers rock. For the Playing Cards condition, the Ace may act as either "high" or "low": Ace beats King, King beats 2, 2 beats the Ace. The stimuli for the Geometric Shapes and Geometric Shapes-Unitized conditions used known objects for which the relations were unknown before the experiment, whereas the stimuli for the Abstract Objects and Abstract ObjectsUnitized conditions were novel, and the relations among them were previously unknown. These varying stimulus conditions ensured that any observed deficit was not due to a global deficit in the processing (RPS, Cards), rather than the learning, of relations (Shapes, Abstract Objects), and further allowed for specification of any observed deficits to learning of relations only (Geometric Shapes) versus the learning of objects as well as their respective relations (Abstract Objects).

\section{Procedures}

An overview of the experimental sessions and the rationale for procedural differences between sessions are provided in Table 4.

Sessions 1-3. Sessions 1-3 used our previously established procedures of standard training plus immediate test (Moses et al., 2008) to contrast
D.A.'s and K.C.'s TP performance with those of control participants. Stimuli were grouped into three completely overlapping pairs $(\mathrm{A}+\mathrm{B}-$, $\mathrm{B}+\mathrm{C}-$, and $\mathrm{C}+\mathrm{A}-$ ) within each condition (RPS, Playing Cards, Geometric Shapes, and Abstract Objects). Training procedures were analogous to those used in our prior work (Moses et al., 2006, 2008). Participants were not informed of any relationships among the stimuli, and were required to learn by trial and error. Instructions stated that the participant would be presented with two objects and their task was to pick one; the computer would provide feedback as to whether they were performing the task correctly. A correct response was rewarded with a happy-face cartoon and the caption "Good Job!," and incorrect responses were followed by an angry-face cartoon and the caption "Wrong!" (Fig. 1b).

Training involved five stages. In stage 1 , participants were presented with 10 trials of one pair $\left(10^{\star} \mathrm{AB}\right)$ followed by 10 trials of the next pair $\left(10^{\star} \mathrm{BC}\right)$, and, finally, 10 trials of the final pair $\left(10^{\star} \mathrm{CA}\right)$. Stage 2 consisted of five presentations of each of the problem pairs $(\mathrm{A}+\mathrm{B}-, \mathrm{B}+\mathrm{C}-$, and $\mathrm{C}+\mathrm{A}-$ ) in consecutive order. Stage 3 was divided into three blocks, and each block was composed of three presentation of each of the pairs in consecutive order. Stage 4 consisted of each problem presented once in consecutive order for nine trials. Stage 5 was composed of two blocks in which each problem was presented 18 times in pseudorandom order, for a total of 108 trials. If participants did not obtain an accuracy of $50 \%$ correct on any of the training blocks, the block was repeated. Following training, participants immediately underwent a test block composed of 12 trials (4 of each pair).

Sessions 4-7. As noted in the Results, D.A., but not K.C., showed intact TP in Sessions 1-3 on conditions for which the relations among the objects had to be learned within the experimental session. To determine whether D.A.'s successful performance was solely due to extended online maintenance of the relations, in Sessions 4-7 D.A. was given the same TP procedures as in Sessions 1-3 with an additional test block of 12 trials ( 4 of each pair) that was given at least $1 \mathrm{~h}$ following the immediate test block. Comparative data were also obtained from control participants, and R.F.R. using the training, immediate test, and 1-h-delay test procedures.

Sessions 8-10. D.A.'s pattern of performance in Sessions 1-7 and his verbal reports suggested that he used unitization strategies to support TP performance. Sessions 8-10 explored whether explicit training with unitization would lead to successful performance in D.A., K.C., and R.F.R. Training and test procedures for Sessions 8-10 unfolded in a similar manner as Sessions 1-7, with the following exceptions. The amnesic patients were presented with the conditions in the following order in each session: Rock-Paper-Scissors, Geometric Shapes, Abstract Objects, Geometric Shapes-Unitized, and Abstract Objects-Unitized. New sets of stimuli were used for the Geometric Shapes-Unitized and Abstract Objects-Unitized conditions (Fig.a). The unitization conditions were presented at the end of the experimental session so as to not unduly bias response strategies 


\section{a Stimuli}

Known objects, Known relations: Rock-Paper-Scissors (RPS):

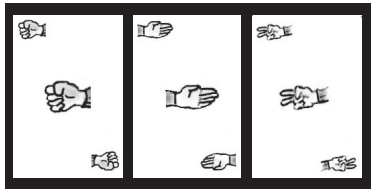

Playing Cards:

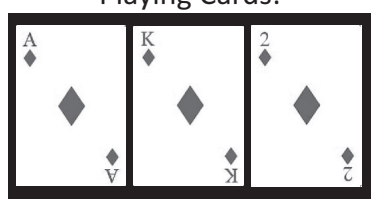

Known objects, Unknown relations:

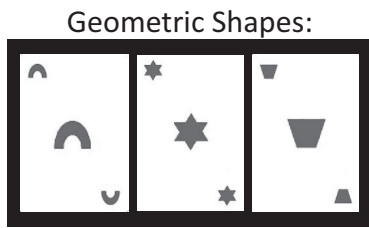

Geometric Shapes Unitized:

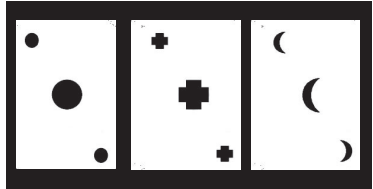

Unknown objects, Unknown relations:

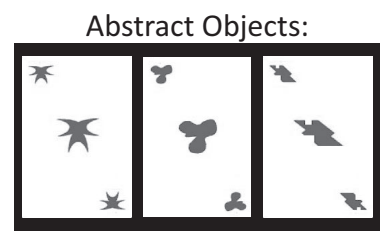

Abstract Objects Unitized:

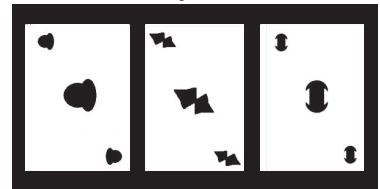

\section{b Experimental procedure}

1. For Unitized conditions only: Movie clips to encourage unitization (select still images displayed here)

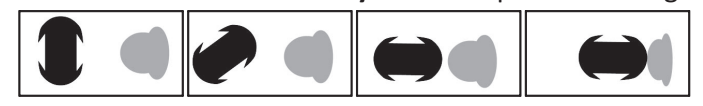

2. Standard Training:

Pairs presented in blocks of 10 (stage 1), 5, (stage 2), 3 (stage 2), 1 (stage 4), and pseudorandomly (stage 5)
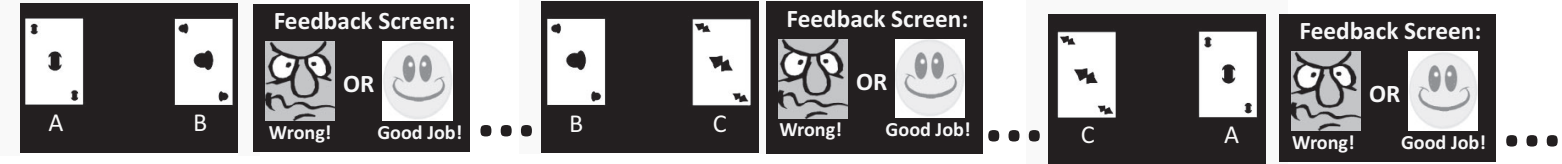

2. Unitized Training:

Pairs presented with unitization reminder cue in blocks of 10 (stage 1), 5, (stage 2), 3 (stage 2), 1 (stage 4), and pseudorandomly (stage 5)
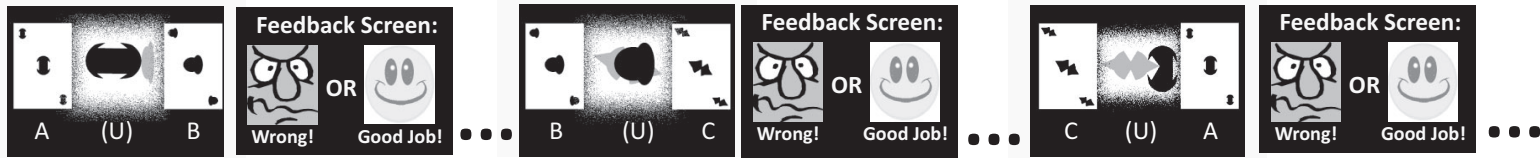

3. Test: Procedure identical for Standard and Unitized, and for Pre-test, Immediate Test, and 1-hour Delay Test

Pairs presented with no cue and no feedback in pseudorandom order 4 times each ( 12 trials in total)
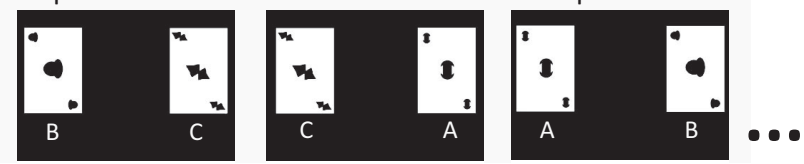

Figure 1. Stimuli and training procedures. $\boldsymbol{a}$, Stimuli used for the Rock-Paper-Scissors, Playing Cards, Geometric Shapes, Abstract Objects, Geometric Shapes-Unitized, and Abstract ObjectsUnitized conditions. Conditions that use objects and relations that were known before the experimental sessions, and before neurological insult for the amnesic patients, include RPS and Playing Cards. The Geometric Shapes and the Geometric Shapes-Unitized conditions used objects that were pre-experimentally known, but the relations among them were unknown. The Abstract Objects and the Abstract Objects-Unitized conditions used objects and relations that were pre-experimentally unknown. Therefore, the varieties of stimuli used allowed for any variations in TP performance to be examined when the objects and/or the relations were unknown before the experimental session. $\boldsymbol{b}$. Training procedures. $\boldsymbol{b}, 1$, Example stills from the flash animations that were shown before the training for the unitized conditions. Flash animations depicted one object physically interacting with the other object through the relations of squish, cover, or pierce. $\boldsymbol{b}, 2$, Training procedures. Standard training presented two stimuli, one on each side of the screen, and participants were required to select the correct item that "wins. " Responses are self-paced and feedback is provided. Unitized training proceeded in the same manner as standard training, except that a still image from the animation was included in the center of the stimulus display (" $(U)$ ") to serve as "hint" for which stimulus was correct. Note that the stimuli are also shown by their corresponding letter (A-C, U) for ease of illustration; however, such letters were not presented to the participants. $\boldsymbol{b}$, 3, Test procedures. All test blocks, regardless of whether training was standard or unitized, and regardless of whether the test was a pretest, immediate test, or 1-h-delay test, followed the same procedures and showed the same stimulus arrangement to the participants.

for other conditions. Before each unitization condition, the patients were presented with flash animations that depicted an interaction between the two objects. The amnesic patients were asked to indicate which object was the "winner" versus "loser" for each of three animations within each condition. The amnesic patients were informed that a final, still, image would remain in the center of each display to serve as a cue for correct response selection during training. During the test stage, this center cue image was removed, and the test display and procedures occurred in the same manner as in the nonunitized conditions: the two stimuli were presented on either side of the screen, and response selections occurred with no feedback. Thus, the only difference between the unitized and nonunitized conditions was the manner of training; the test procedures were identical. The training stages, along with the number of trials, remained the same as in Sessions 1-7 for all conditions. Immediate and 1-h-delay tests were given.

Session 11. Session 11 was conducted to determine the extent to which D.A.'s continually high TP performance would be retained following a delay of 1 week. Session 11 proceeded in a similar manner as Sessions $8-10$; however, pretests were administered before any training on any of the conditions to examine retention of the previously learned TP relations. The pretests were identical in procedures to the final test stage as 
Table 4. Overview of the procedures for each experimental session

\begin{tabular}{|c|c|c|c|c|c|c|c|}
\hline \multirow[b]{2}{*}{ Session } & \multicolumn{2}{|l|}{ Pretest } & \multicolumn{2}{|l|}{ Training } & \multicolumn{2}{|l|}{ Test } & \multirow[b]{2}{*}{ Rationale } \\
\hline & 1 week & 1 month & Standard & Unitized & Immediate & $1 \mathrm{~h}$ & \\
\hline $1-3$ & & & V & & V & & $\begin{array}{l}\text { Standard TP training and immediate test as in } \\
\text { Moses et al. (2008) }\end{array}$ \\
\hline $4-7$ & & & V & & V & V & $\begin{array}{l}\text { Inclusion of 1-h-delay test to determine whether } \\
\text { successful performance is due to online } \\
\text { maintenance of relations }\end{array}$ \\
\hline $8-10$ & & & V & V & V & V & $\begin{array}{l}\text { Inclusion of unitized training procedures to } \\
\text { determine whether D.A.'s spontaneous strategy } \\
\text { can support performance for other patients and } \\
\text { in other conditions }\end{array}$ \\
\hline 11 & V & & V & V & V & V & $\begin{array}{l}\text { Pretest added following a } 1 \text { week delay to examine } \\
\text { retention of relations }\end{array}$ \\
\hline $12-13$ & & V & V & & V & V & $\begin{array}{l}\text { Extended (1 month) delay between prior testing } \\
\text { sessions and current pretest; unitized training } \\
\text { removed to examine robustness of prior learning }\end{array}$ \\
\hline
\end{tabular}

$\checkmark$, Procedure included in experimental session.

given in all of the previous sessions (i.e., 12 trials without feedback, 4 trials for each pair of stimuli). Pretests were given in the following order: Geometric Shapes, Abstract Objects, Geometric Shapes-Unitized, and Abstract Objects-Unitized. Note here that "Unitized" for the Geometric Shapes-Unitized and the Abstract Objects-Unitized conditions refers to the training procedures and stimuli that had been presented in Sessions 8-10; unitization training procedures were not given before the pretest. A pretest for RPS was not given so as to not provide D.A. with any hints regarding the overall problem structure. Following the pretests, training, immediate, and 1-h-delay tests proceeded for the RPS, Geometric Shapes, Abstract Objects, Geometric Shapes-Unitized, and Abstract Objects-Unitized conditions, as in Sessions 8-10.

Sessions 12 and 13. Sessions 12 and 13 were conducted to examine the extent to which D.A. would exhibit successful TP performance on pretests that were given following a delay of 1 month. Training, immediate, and 1-h-delay tests were then given as in Sessions 8-11 with the following exception: to further examine the robustness of prior learning, unitization training procedures were not provided in Sessions 12 and 13, although the stimuli and response conditions for Geometric ShapesUnitized and Abstract Objects-Unitized remained the same as in Sessions 8-11. Therefore, the term Unitized for Geometric Shapes-Unitized and Abstract Objects-Unitized in Sessions 12 and 13 refers to the manner of prior training in Sessions 8-11.

\section{Statistical analysis}

A 95\% confidence interval (CI) was established around the mean accuracy for the control participants where applicable. Mean or singleobservation accuracies obtained for the amnesic patients were contrasted against the $95 \%$ CI of the control participants; performance was considered to be intact if the observed accuracy of the amnesic patient fell within the this control range, performance was considered to be impaired if the observed accuracy fell outside this control range.

\section{Results}

A summary of the testing sessions, including the patients tested, the conditions completed, and the resultant performance, is presented in Table 5.

\section{Sessions 1-3: immediate testing of TP for previously known and unknown relations}

In Sessions 1-3, D.A. was presented with four conditions of TP, which varied according to whether the three presented objects and/or the relations among them had been known before neuro- logical insult, as follows: (1) RPS (known objects, known relations); (2) Playing Cards (known objects, known relations); (3) Geometric Shapes (known objects, unknown relations); and (4) Abstract Objects (unknown objects, unknown relations) (Fig. 1a). The Shapes and Abstract Objects conditions required the participants to learn, through feedback, the novel relations among pre-experimentally known or unknown objects, respectively. As in Moses et al. (2008), training was provided in five stages, with each problem pair presented repeatedly, initially in consecutive order (Stage 1) and eventually in pseudo-random order (Stage 5). Training was immediately followed by a nofeedback test block of 12 trials ( 4 of each pair; Fig. $1 b$ ). The following results refer to performance on that no-feedback test block.

As reported in Moses et al. (2008), K.C. completed all TP conditions three times in separate sessions, and 13 control individuals who were age- and education-matched to D.A. and K.C. (age range, 49-61 years; mean age, 55 years) participated once in each condition. Data from K.C. and the controls (Moses et al., 2008) are re-presented here for comparison with D.A. In Session 1 , due to time constraints, D.A. was only able to complete the test sessions for the RPS and Cards conditions, for which performance was $100 \%$ and $83 \%$, respectively. Accuracy on the Cards condition fell outside of the $95 \%$ CI for controls. D.A. received all four conditions in Sessions 2 and 3. In Session 2, D.A.'s accuracy was within the $95 \%$ control CI only for RPS; however, by Session 3 , D.A.'s accuracy was within the control range for all four conditions (Fig. 2).

D.A. was asked to describe his understanding of the relations among the objects (i.e., which object wins in each problem) immediately following each of the test blocks. Across sessions, he consistently remarked that he knew the relations for RPS, as he had used this game with his childhood friends as a means to select players for teams. He also expressed knowledge of the relations for Playing Cards, as acquired from childhood card games. For Shapes, D.A. based his choices on what object he believed "..could cover the other" (Session 2). For Abstract Objects, D.A. created interactions among the objects, such that the objects would become physically entwined, with 
Table 5. Summary of experimental sessions, including the conditions tested, the amnesic patients tested and their resultant performance

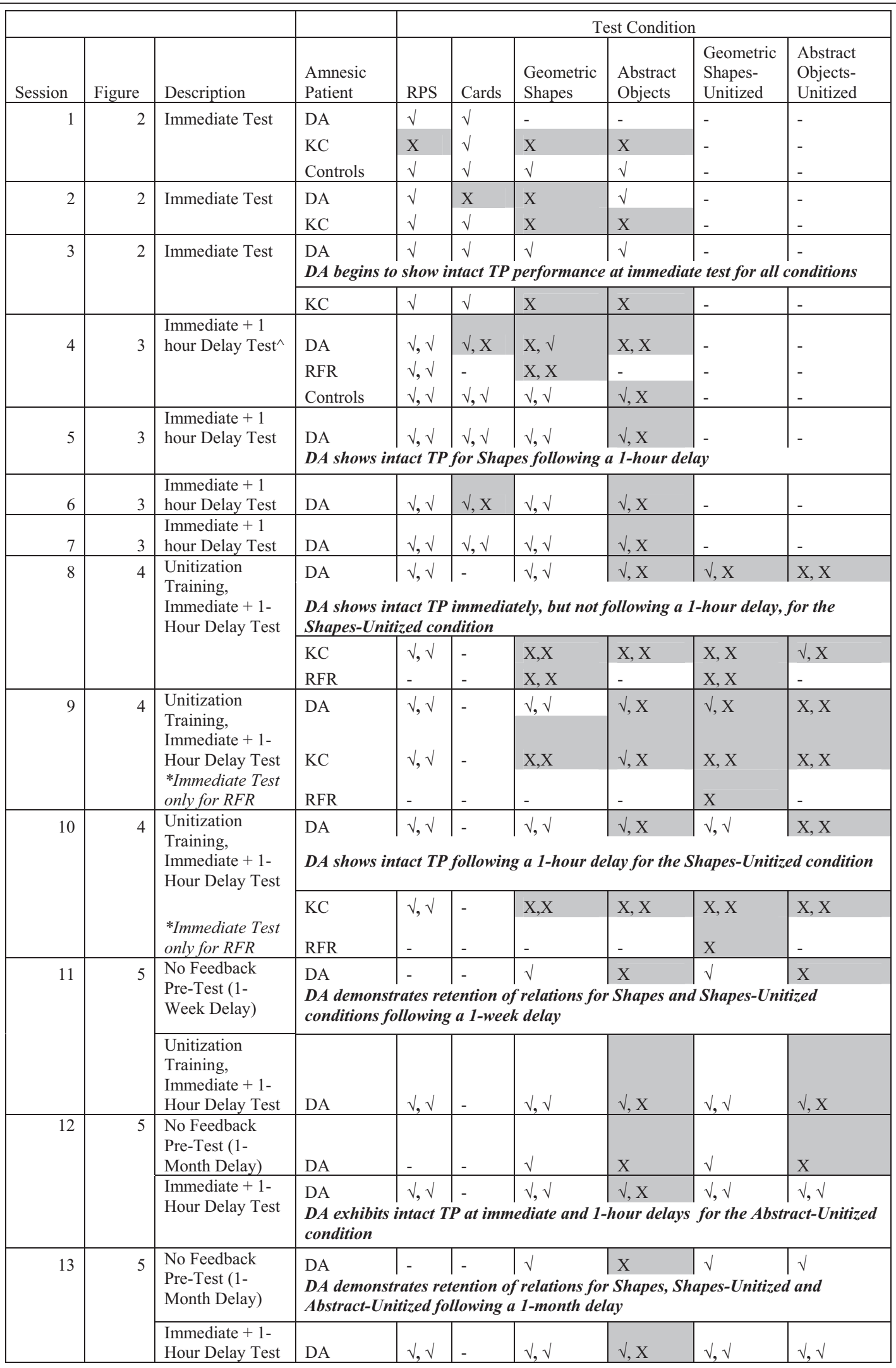




\section{Immediate Test}

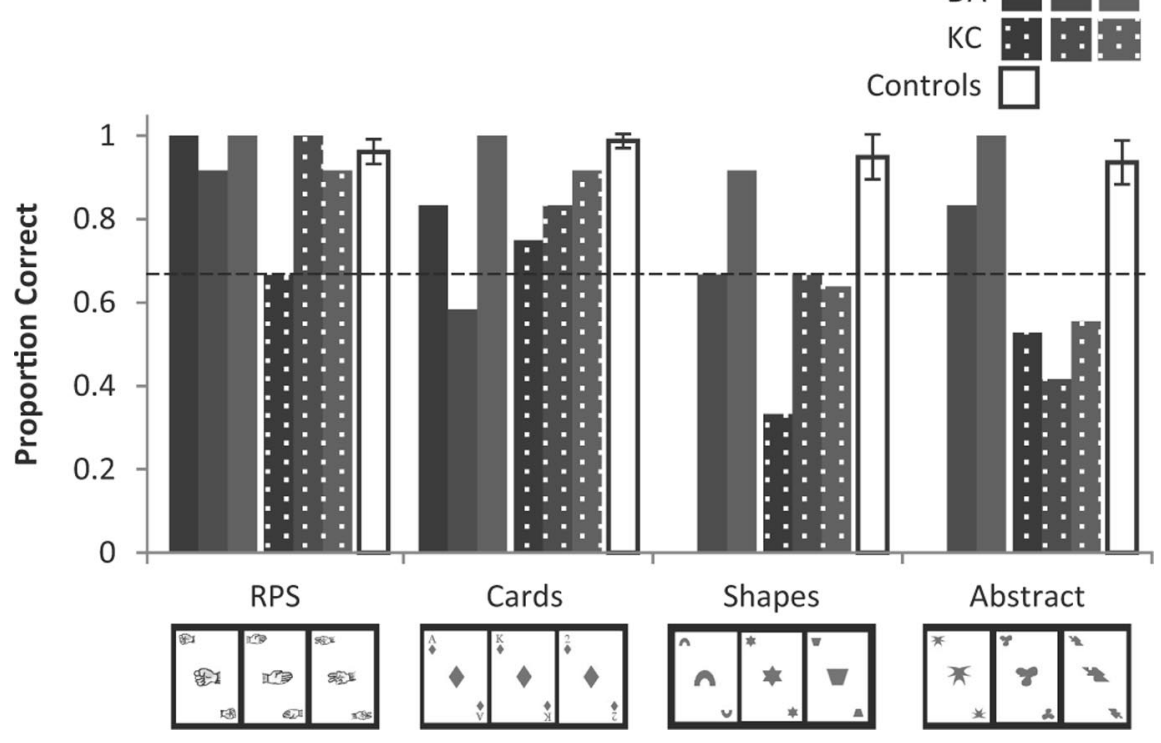

Figure 2. TP performance for D.A. and K.C. (Sessions 1-3). Accuracy (percentage correct) on the no-feedback test conditions of transverse patterning (Rock-Paper-Scissors, Playing Cards, Geometric Shapes, and Abstract Objects) for amnesic patients K.C. and D.A. and control participants. The test condition was administered immediately following the training session, on which feedback was provided. Data from K.C. and the controls are re-presented from Moses et al. (2008). The $95 \%$ confidence interval is shown for the control mean. K.C. and D.A. were tested in each condition once in each of three separate sessions (Sessions 1-3). Control subjects were tested in a single session. Due to time constraints, D.A. was only able to complete the test sessions for RPS and Cards conditions in the first session. The dashed line denotes the $67 \%$ elemental maximum, indicative of an elemental strategy. The number beside the patient's initials corresponds to the testing session, as outlined in Table 5. D.A. and K.C. alike show predominantly intact TP for the conditions in which the objects and the relations among them were known before their neurological insults (RPS, Cards). By Session 3, D.A. also shows intact TP performance at immediate test for conditions in which the relations were unknown before his neurological insult (Geometric Shapes, Abstract Objects); whereas K.C. continued to show impaired performance.

one object ultimately emerging as the victor (e.g., Session 2: "blob could cover star's points and dull it"). However, this physical unitization was not consistently applied across the Abstract Objects pairings in Session 3 (e.g., "dog braying at the moon and stars"). K.C., who was reliably impaired on Shapes and Abstract Objects, did not integrate objects and instead selected "...the one that seems better".

\section{Sessions 4-7: immediate versus $1 \mathrm{~h}$ delayed testing of TP}

Unlike K.C., D.A.'s performance in Session 3 resembled that of controls on all conditions. Sessions 4-7 investigated whether D.A.'s intact performance was a result of extended on-line maintenance of the presented relations (i.e., working memory) by providing an additional test block $1 \mathrm{~h}$ following the immediate test block. Since K.C. never performed within the control CI for either the Shapes or Abstract condition, K.C. was not tested in Sessions 4-7. Accuracy data for D.A. was compared with that of 10 age-matched (53 years; age range, $50-57$ years) and education-matched (17 years; education range, $12.5-21$ years) controls who were tested in one session, and additional comparative data were obtained from R.F.R., who was also tested in one session. At immediate testing, D.A. largely showed retention of both pre-experimentally acquired and novel relations across all sessions (Fig. 3a). Following a 1 h delay, D.A.'s mean accuracy remained within the 95\% control CI for RPS, Playing Cards, and Shapes. D.A.'s mean accuracy for Abstract Objects (Fig. 3b) was far below the $67 \%$ elemental theoretical maximum, which represents successful performance on two of the three pairs, and can be accomplished by learning reward value of the single items rather than relations among the items (Rickard et al., 2006). Performance above the $67 \%$ threshold is traditionally thought to signify that the relations among the items have been learned.

Examination of D.A.'s verbal responses for Shapes again revealed that D.A. concocted object names and stories in which the objects were made to physically interact with one another (e.g., "star fills bucket", "bucket covers rainbow"). D.A. did not integrate the objects for Abstract Objects in Sessions 4-7 (e.g., "Snoopy beats the witch," "The witch beats the blotch," "The blotch beats Snoopy"; note that D.A.'s use of the word "beats" was used to convey "wins over" rather than "hits"), although he had devised names for the objects, which were consistently invoked. In the absence of such integration in Sessions 4-7, D.A. (like K.C.) was impaired at maintaining relations across a delay.

Due to time constraints, R.F.R. only completed training and testing for RPS and Shapes. R.F.R. performed well on RPS at immediate test and after a $1 \mathrm{~h}$ delay; however, accuracy was well below $67 \%$ on Shapes at both immediate and $1 \mathrm{~h}$ delays (Fig. 3a,b). Thus, R.F.R. showed normal memory and use of relations that were known before his neurological insult (RPS), but was impaired on establishing new relations, even among known objects (Shapes). Like K.C., R.F.R. did not spontaneously attempt to unitize or fuse the objects presented in the Shapes condition.

\section{Sessions 8-10: explicit training of a unitization strategy}

Subsequent testing sessions with D.A., K.C., and R.F.R. were conducted to explore whether explicit use of the unitization strategy could improve TP performance, particularly for K.C. and R.F.R., who did not previously show any success on TP, or whether it is critical for unitization strategies to be self-initiated, as could be the case for D.A. Control subjects were not tested under unitization procedures given that performance was already at ceiling without such training. Patients were given the following five conditions: (1) RPS; (2) Geometric Shapes; (3) Geometric ShapesUnitized; (4) Abstract Objects; and (5) Abstract ObjectsUnitized. RPS, Geometric Shapes, and Abstract Objects conditions were conducted as in previous sessions, and two new sets of stimuli were created for the Unitized conditions (Fig. 1a). Before training on the Unitized sets, the patients were presented with three flash animations in which each pair of two objects was shown to interact through one of three actions: one object squishing another, one object covering another, or one object piercing another (Fig. 1b). The animation ended with the two objects physically connected in a manner that depicted the winner versus the loser. In Unitized Session 1, the patients were asked to describe the animations and to select the winner versus loser. During training, the final still image from the animation was placed in the center of the display to 


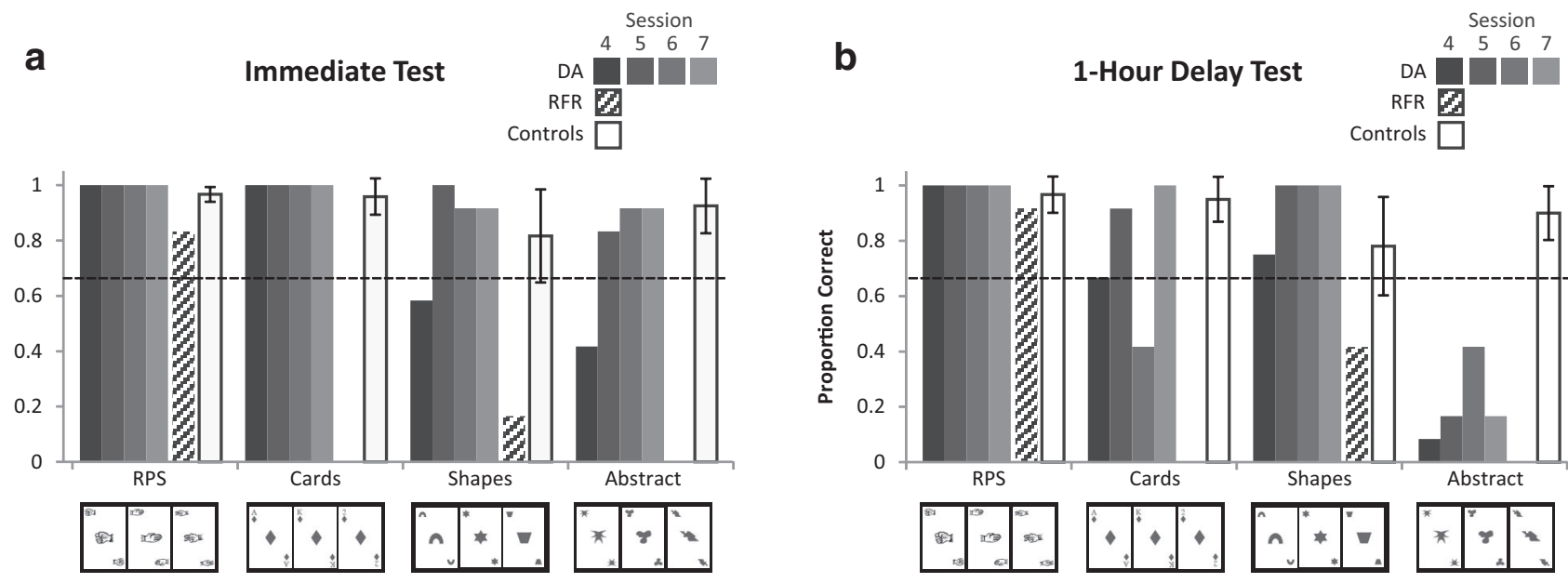

Figure 3. Predominantly intact TP performance for D.A. at immediate and 1-h-delay test (Sessions 4-7). $\boldsymbol{a}, \boldsymbol{b}$, Accuracy (percentage correct) on the no-feedback test conditions of transverse patterning (Rock-Paper-Scissors, Playing Cards, Geometric Shapes, and Abstract Objects) immediately following training (a) and following a $1 \mathrm{~h}$ delay (b) for amnesic patient D.A., R.F.R., and control participants. The $95 \%$ confidence interval is shown for the control mean. Procedures were the same as in Sessions 1-3, except for the inclusion in Sessions $4-7$ of an additional test block that was provided at the $1 \mathrm{~h}$ delay. D.A. was tested in each condition once in each of the four separate sessions. R.F.R. was tested in Session 4 for the RPS and Shapes conditions only. Control participants were tested in a single session. The dashed line denotes the $67 \%$ elemental maximum, indicative of an elemental strategy. The number beside the patient's initials corresponds to the testing session, as outlined in Table 5. R.F.R. showed intact TP when the objects and the relations among them were known before his neurological insult (RPS), but impaired TP for the Geometric Shapes condition, which required learning of the relations among known objects. By contrast, D.A. showed intact TP for RPS and Cards (pre-experimentally known objects and relations), and showed intact performance by Session 5 for the Shapes condition (pre-experimentally known objects, but unknown relations), both immediately and following a $1 \mathrm{~h}$ delay. D.A.'s performance for the Abstract Objects (unknown objects, unknown relations) remained low following a $1 \mathrm{~h}$ delay.

a Immediate Test

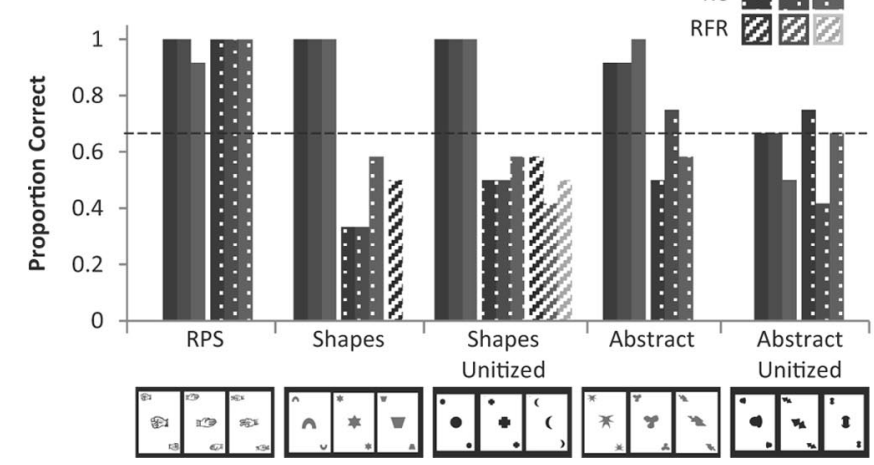

b

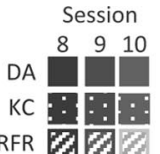

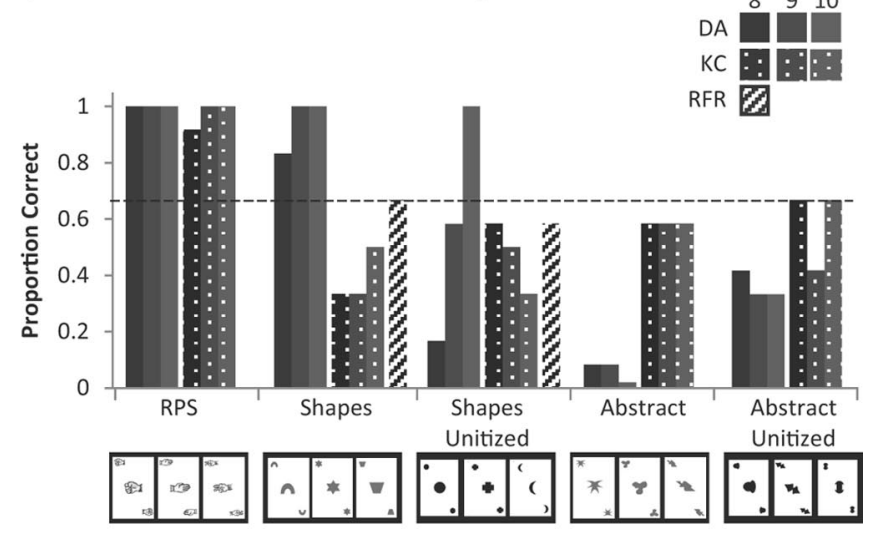

Figure 4. TP with and without Unitization procedures at immediate and 1-h-delay test for D.A., K.C., and R.F.R. (Sessions 8 -10) Accuracy (percentage correct) on the no-feedback test conditions of transverse patterning that either did (Shapes-Unitized, Abstract-Unitized) or did not (Rock-Paper-Scissors, Shapes, Abstract Objects) employ unitization training procedures. $\boldsymbol{a}, \boldsymbol{b}$, Test conditions were presented immediately following training ( $\boldsymbol{a}$ ) and following a $1 \mathrm{~h}$ delay $(\boldsymbol{b})$ for amnesic patients D.A., K.C., and R.F.R. D.A. and K.C. were tested in each condition once in each of three separate sessions. R.F.R. completed the immediate and 1-h-delay test for the Shapes and Shapes Unitized conditions in Session 8, and the immediate test of the Shapes-Unitized condition for Sessions 9 and 10 only. During training (feedback provided) in the Unitized sessions, the final still image of the two objects interacting was placed in the center of the display to serve as a guide for response selection, but during the test condition this center image was removed. The dashed line denotes the $67 \%$ elemental maximum, indicative of an elemental strategy. The number beside the patient's initials corresponds to the testing session, as outlined in Table 5. R.F.R. did not show improvements in TP under unitized training conditions at either immediate or 1-h-delay testing. D.A. showed intact TP for the Shapes-Unitized condition at immediate testing in Sessions $8-10$, and at a $1 \mathrm{~h}$ delay by Session 10. D.A.'s performance on the Shapes condition (known objects, unknown relations) continued to remain high immediately and following a $1 \mathrm{~h}$ delay across Sessions 8-10, but performance on each of the Abstract Objects (unknown objects, unknown relations) conditions remained low at the $1 \mathrm{~h}$ delay, regardless of training procedures.

serve as a guide for response selection (Fig. $1 b$ ). During the final test block, no center image was provided. Test blocks were administered immediately following training and after a 1 h delay.

\section{D.A.: session 8}

At immediate testing, D.A. performed at or near $100 \%$ accuracy for the RPS, Shapes, Shapes-Unitized, and Abstract conditions (Fig. 4a). Performance for the Abstract-Unitized condition was at the $67 \%$ threshold. At the $1 \mathrm{~h}$ delay, 100\% accuracy was maintained for RPS; accuracy for Shapes remained high (83\%), but accuracy for the Shapes-Unitized, Abstract, and AbstractUnitized conditions were well below 67\% (Fig. 4b). Contrary to expectations, performance for D.A. on the unitized conditions was lower than that of the nonunitized conditions. However, query of D.A.'s interpretation of the animations revealed that D.A. had considered the experimentally defined winners to actually be the losers, and vice versa. This occurred because the animations were played on a continuous loop, and rather than interpreting the interaction as one object being squished by another, for instance, D.A. interpreted the interaction as one object 
Table 6. Training data (average accuracy and average number of trials to complete training) for DA, KC, and RFR on the RPS, Geometric Shapes, Abstract Objects, Shapes-Unitized, and Abstract-Unitized conditions across sessions

\begin{tabular}{|c|c|c|c|c|c|c|c|}
\hline \multirow[b]{2}{*}{ Amnesic patient } & \multirow[b]{2}{*}{ Sessions } & \multirow[b]{2}{*}{ Measure } & \multicolumn{5}{|l|}{ Condition } \\
\hline & & & RPS & Geometric Shapes & Abstract Objects & Shapes-Unitized & Abstract-Unitized \\
\hline \multirow[t]{2}{*}{ D.A. } & $8-13$ & Accuracy (SD) & $0.99(0)$ & $0.96(0.03)$ & $0.97(0.03)$ & $0.96(0.02)$ & $0.93(0.06)$ \\
\hline & & No. of trials (SD) & $207(0)$ & $207(0)$ & $207(0)$ & $207(0)$ & $208.5(3.67)$ \\
\hline \multirow[t]{2}{*}{ K.C. } & $8-10$ & Accuracy (SD) & $0.99(0.01)$ & $0.55(0.05)$ & $0.53(0.03)$ & $1.00(0.00)$ & $1.00(0.00)$ \\
\hline & & No. of trials (SD) & $207(0)$ & $282(44.40)$ & $232(22.72)$ & $207(0)$ & $207(0)$ \\
\hline \multirow[t]{2}{*}{ R.F.R. } & $8,8-10$ & Accuracy (SD) & & 0.52 & & $0.92(0.09)$ & \\
\hline & & No. of trials (SD) & & 234.00 & & $207(0)$ & \\
\hline
\end{tabular}

D.A. demonstrates near perfect performance during training across all conditions. K.C. demonstrates near perfect training performance for RPS (known objects with known relations). K.C.'s training accuracy is low for Geometric Shapes and Abstract Objects; however, K.C.'s performance is at or near perfect throughout training across sessions when unitization procedures are implemented (Shapes-Unitized, Abstract-Unitized). Similar to K.C., R.F.R.'s training accuracy is consistently higher when unitization procedures are used.

throwing the other object into the air. Despite attempts to steer D.A. onto the alternate interpretation, he consistently responded with the inverse winner/loser mappings, perhaps due to abnormal perceptual construction of the stimuli (Lee et al., 2012) and/or merely due to the persistent use of an established selfgenerated strategy. Since D.A.'s interpretations of the animations were not consistent with the experimental response mappings, task instructions were changed in subsequent sessions.

\section{D.A.: sessions 9 and 10}

In Sessions 9 and 10, the flash animations for the unitized conditions were presented and verbally described by the experimenter (J.D.R.), without using names for the objects (e.g., "One object is moving over to cover the other object"). D.A.'s accuracy remained at or near $100 \%$ for the RPS, Shapes, Shapes-Unitized, and Abstract conditions at immediate testing; accuracy for the Abstract-Unitized condition remained at or below 67\% (Fig. 4a). At the $1 \mathrm{~h}$ delay, accuracy was $100 \%$ for RPS and Shapes in Sessions 2 and 3, and for Shapes-Unitized in Session 3. Accuracy remained well below $67 \%$ for Abstract and Abstract-Unitized (Fig. $4 b$ ). Thus, D.A. was able to learn a novel set of relations for pre-experimentally known objects (Shapes), but was not able to learn novel relations for relatively novel objects (Abstract Objects; Fig. 4a,b).

\section{K.C. and R.F.R.: sessions $8-10$}

For K.C., performance for RPS remained high at immediate and delayed testing, but was at or below $67 \%$ for the remaining conditions across each of the three sessions. Training accuracy was substantially improved for K.C. through unitization, similar to the training accuracy exhibited by D.A. (Table 6), but these gains did not transfer to the test block when the unitized image was removed from the display.

In Session 8, R.F.R. completed the training and immediate no-feedback test and the 1-h-delay test for the Shapes and Shapes-Unitized conditions. Accuracy was at or below $67 \%$ for each condition at immediate testing and at the $1 \mathrm{~h}$ delay (Fig. $4 a, b)$. In Sessions 9 and 10, only the training and immediate no-feedback test for the Shapes-Unitized condition were given, due to time constraints, and R.F.R.'s accuracy (42\% and 50\%) remained below $67 \%$. Similar to K.C., R.F.R.'s performance during training on the unitized conditions was highly accurate (Table 6), but this was not maintained in the test condition when the fused image was removed from the display.

\section{Sessions 11-13: testing of extended delays}

Session 11 (1 week delay)

To determine whether D.A.'s successful performance could be retained over an extended delay, Session 11 was conducted with
D.A. 1 week following Session 10, and began with a no-feedback pretest for the Shapes, Abstract, Shapes-Unitized, and AbstractUnitized conditions before any training. The no-feedback test condition for RPS was not used during the pretest phase so as not to provide any additional clues to D.A. regarding task requirements. At pretest, D.A. performed above 67\% for Shapes and Shapes-Unitized, but below $67 \%$ for Abstract and AbstractUnitized (Fig. 5a). Thus, learning was retained only for the preexperimentally known shapes, but not the (relatively) novel abstract objects. The pretest was then followed by the same procedures as in Sessions 8-10 (i.e., training plus feedback, immediate test, 1-h-delay test). D.A. performed near the ceiling on the immediate test for all conditions, but his performance fell well below 67\% for Abstract and Abstract-Unitized following a $1 \mathrm{~h}$ delay (Fig. 5b,c).

\section{Session 12 (1 month delay)}

Session 12 was conducted 1 month following Session 11 to determine the stability of D.A.'s performance. Accuracy patterns for the no-feedback pretest largely resembled those for Session 11 (Fig. 5a). Following the pretest, training was again conducted in Session 12; however, no animations were shown and no fused center stimuli were provided during training for the ShapesUnitized and the Abstract-Unitized conditions so that, procedurally, the Unitized and the nonunitized conditions would be same; the only difference would be D.A.'s training history for the conditions. This allowed us to determine whether D.A.'s performance would remain high for the Unitized conditions even when the unitized movies and fused center stimuli were no longer provided. D.A.'s accuracy on the immediate test was at or near ceiling for all conditions (Fig. 5b). Following the $1 \mathrm{~h}$ delay, 100\% accuracy remained for RPS, Shapes, and Shapes-Unitized; accuracy was at $0 \%$ for the Abstract condition, as observed in Unitized Session 4 (Fig. $5 c$ ). However, D.A.'s accuracy at the $1 \mathrm{~h}$ delay for Abstract-Unitized improved from 33\% in Session 4 to $92 \%$ in Session 12.

\section{Session 13 (1 month delay)}

Session 13 was conducted 1 month following Session 12. The no-feedback pretest revealed accuracy that was well above $67 \%$ for the Shapes, Shapes-Unitized, and Abstract-Unitized conditions (Fig. 5a). Thus, the learning that was exhibited by D.A. for Abstract-Unitized at the end of Session 12 was retained 1 month later. Accuracy for the Abstract condition, for which unitization strategies were never provided in any session, remained at floor. Training with immediate no-feedback testing was again conducted in Session 13; however, as in Session 12, neither the animations nor the central fused stimuli were provided for the Shapes-Unitized and the Abstract-Unitized conditions. D.A. per- 
a

Pre-test: 1-week (DA 11) \& 1-month (DA 12, DA 13)

Session

111213

DA

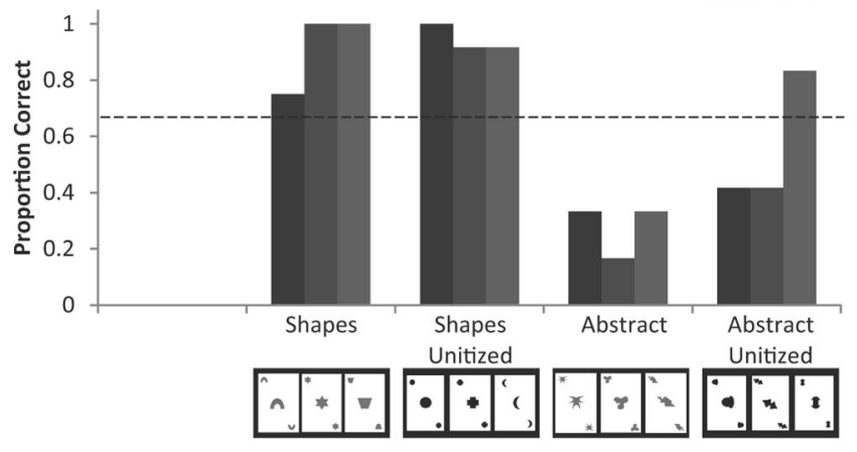

b

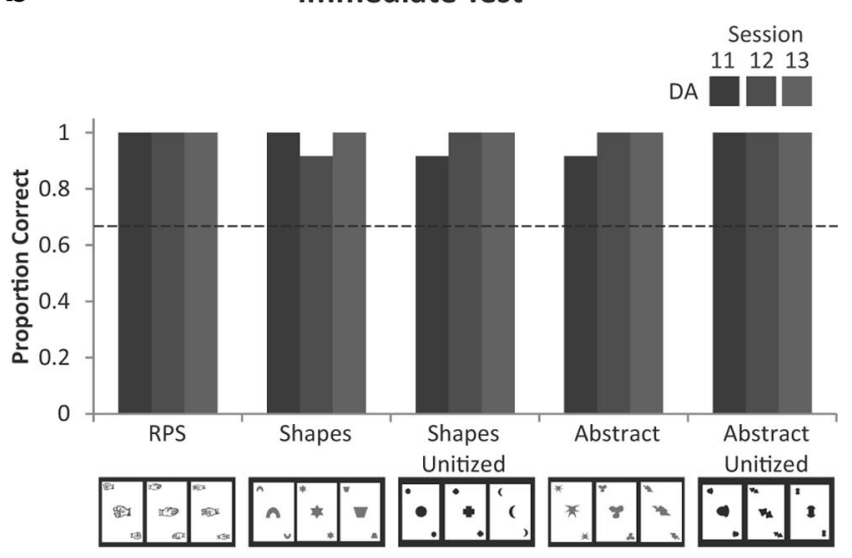

C

1-hour Delay Test

$\begin{array}{lll}11 & 12 \quad 13\end{array}$

DA

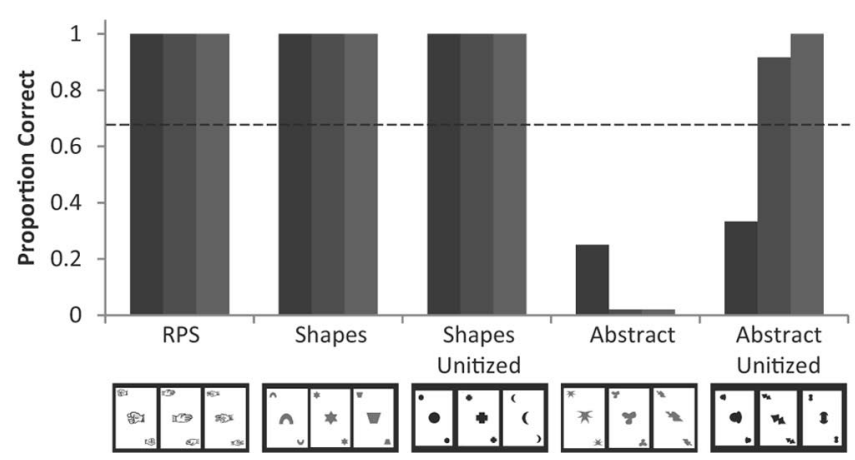

Figure 5. Lasting TP performance for D.A. under unitization procedures following extended delays of 1 week and 1 month (Sessions 11-13). Accuracy (percentage correct) on the no-feedback test conditions of transverse patterning that either did (Shapes-Unitized, Abstract-Unitized) or did not (Rock-Paper-Scissors, Shapes, Abstract Objects) use unitization training procedures. $\boldsymbol{a}-\boldsymbol{c}$, Test conditions were presented to amnesic patient D.A. before any training ( $\boldsymbol{a}$; pretest following either a 1 week or 1 month interval from previous session), immediately following training (b) and following a $1 \mathrm{~h}$ delay (c). D.A. was tested in each condition once in each of three separate sessions. RPS was not given at pretest to not unduly influence performance on the other conditions through analogical transfer of the response scheme. Note that although the central unitized image was not provided during training for the Shapes-Unitized and Abstract-Unitized conditions of Sessions 12 and 13 , the term Unitized here refers the manner of training provided in previous sessions. The dashed line denotes the $67 \%$ elemental maximum, indicative of an elemental strategy. The number beside the patient's initials corresponds to the testing session, as outlined in Table 5. In Session 11, D.A. demonstrated retention of the relations among objects for the Shapes and Shapes-Unitized conditions (known objects, unknown relations) following a 1 week delay. By Session 12, D.A. also exhibited intact TP and immediate and $1 \mathrm{~h}$ delays when Abstract objects were used (unknown objects, unknown relations), but only when unitization training procedures had been used. These gains in performance were maintained following a 1 month delay (Session 13).

formed perfectly on all conditions (Fig. $5 b$ ). Following the $1 \mathrm{~h}$ delay, D.A. performed perfectly on all conditions except the nonunitized Abstract condition, for which D.A. did not get a single problem correct (Fig. 5c).

Inspection of D.A.'s verbal reports revealed that, for the Abstract condition, D.A. did not attempt to unitize or otherwise physically integrate the objects in any session, although he would present a narrative in which one object wins over the other (e.g., "Snoopy beats the witch"). On occasion, D.A. would comment that he would merely select one object to win (e.g., "I just placed it that way"). By contrast, for the Abstract-Unitized condition, D.A. would often report similar relations to what had been presented in the flash animations (Session 13, for the relation of cover: "looks like you could hang your hat on it, like a hanger"; for the relation of pierce: "...so sharp it would rupture the up/ down arrow and split it"; for the relation of squish: "might flip hat over it, but keep pushing out and break rim of hat"). When D.A. was asked how he had devised those stories, he proclaimed that he had made them up himself. When asked explicitly, he denied having seen any movies or pictures.

\section{Discussion}

Here, we report the unique amnesic case of D.A., who succeeds on $\mathrm{TP}$, which requires learning arbitrary relations among items and has been previously shown to critically rely on hippocampal function (Alvarado and Rudy, 1995; Rickard and Grafman, 1998). This work is the first to identify the spontaneous use of a unitization strategy by an amnesic person to support intact performance on a relational memory task, for which performance would otherwise have been impaired. Importantly, such findings highlight that tasks are rarely "process-pure." Consideration should be given to the multiple ways in which a task may be solved, particularly when interpreting patterns of spared and impaired performance in neurological patients.

Studies of TP in nonhuman animals with fornix or hippocampal lesions have produced mixed results, with some studies showing intact performance (Bussey et al., 1998; Brasted et al., 2003; Saksida et al., 2007) and others showing impaired performance (Dusek and Eichenbaum, 1998; Alvarado and Bachvalier, 2005; Driscoll et al., 2005). By contrast, to our knowledge, there are no 
reports of intact TP performance in humans with lesions to the hippocampus and surrounding MTL structures, whether tested following a delay or immediately. Our results indicate that intact TP can be observed in human amnesia, and that this anomaly is due to D.A.'s use of a self-generated unitization-encoding strategy that allows distinct objects to be fused into a single representation from which the necessary relations may be derived. D.A. succeeds on conditions for which he generates a scenario involving the physical integration of objects. When such integration does not occur, performance remains at floor following a delay after initial training. When specifically prompted with the unitization strategy, D.A. could learn the relations among even pre-experimentally novel, abstract objects for which no representation previously existed in memory. Surprisingly, D.A. could select the appropriate relations among the stimuli during non-reinforced sessions that were presented $1 \mathrm{~h}$-and even 1 month-later, demonstrating lasting benefits for memory. By contrast, K.C. and R.F.R. did not self-generate integration scenarios during standard training, and unitization training did not provide any benefits to performance.

Whereas K.C. and R.F.R. could process relations that were acquired before the onset of their amnesic syndromes (RPS, Cards), they were unable to learn novel relations. Under unitization procedures, training accuracy improved considerably for K.C. and R.F.R. High training accuracy, as seen in each of the amnesic patients tested here, stands in stark contrast to low training accuracy on TP in other amnesic studies (Rickard and Grafman, 1998; Reed and Squire, 1999; Rickard et al., 2006). Although training was similar to errorless learning conditions (Glisky et al., 1986), K.C. and R.F.R. did not show consistent and lasting benefits in subsequent test sessions when feedback and the central unitization cue were removed, highlighting the inflexibility of the information that had been learned.

Critically, although D.A. and K.C. had the same training and testing in Sessions 1-3, D.A. showed successful TP for Shapes (Session 3) and Abstract Objects (Sessions 2 and 3), whereas K.C. did not. When unitization training procedures were introduced in Sessions 8-10, D.A. showed intact TP performance at immediate (Sessions $8-10$ ) and 1 h tests (Session 10) for the Shapes-Unitized condition, whereas K.C. and R.F.R. did not show improvements in performance. Although the number of sessions was not identical across patients, K.C. and R.F.R. nonetheless had repeated testing on TP, including multiple unitization training sessions (K.C.: three standard and three unitized sessions; R.F.R.: one standard and three unitized sessions). Nevertheless, K.C. and R.F.R. were not able to achieve a similar level of performance to that of D.A., who showed spontaneous gains within three standard sessions of TP and within two unitized sessions (Shapes). Findings from Quamme et al. (2007) revealed similar variation in the performance of amnesic patients under unitization. Although the amnesic group did not perform like controls on an associative recognition task under unitization encoding instructions, one amnesic person (R.M.) may have performed within the control range (although this was not explicitly discussed).

We propose that unitization as a compensatory mechanism requires visual imagery of multiple items that are fused or otherwise integrated. This fused, multi-item perceptual image is anchored to existing perceptual and/or conceptual representations in semantic memory through extended on-line maintenance. While research has argued for a role for the hippocampus in maintaining relational information on-line over even brief delays
(Olson et al., 2006), research with nonhuman animals demonstrates that, in the face of hippocampal damage, simple relations may be maintained over brief delays via the prefrontal cortex (Winocur, 1992). Such results are consistent with neuroimaging findings showing a particular role for the prefrontal cortex in relational processing and integration (Wendelken and Bunge, 2010; Blumenfeld et al., 2011; Knowlton et al., 2012). Thus, simple relations may be maintained independent of the hippocampus, whereas with increasing visual complexity and number of relations, both the prefrontal cortex and hippocampus are likely needed to maintain the full range of information in an activated state within an on-line representation (for review, see Olsen et al., 2012).

Given that in TP, there were extended training procedures to learn a limited number of relations (three within each stimulus condition), the unitized image could likely be maintained in an active state independent of the hippocampus (Wickelgren, 1968). Maintaining the unitized image on-line during training may be critical for the establishment and continued strengthening of the unitized representation within semantic memory so that it is ultimately available for use following an extended delay. The unitized representation may then be retrieved and queried for the relations that are contained therein.

A critical question remains regarding which neural systems support unitization. The PRC, which may have been considered the most likely candidate for unitization (Barense et al., 2007; Bussey and Saksida, 2005, 2007; Henke, 2010), is almost completely damaged in all patients, including D.A. Damage to the PRC may explain why D.A. required fewer sessions to achieve at-ceiling or near-ceiling performance under unitization training for the Shapes compared with the Abstract Objects condition (Session 10 vs 12). Both conditions forced D.A. to unitize the stimuli; the only difference was in the type of stimuli presented (known vs unknown objects). It is possible that the PRC would be particularly engaged when unitization is invoked for novel objects, but not for objects for which representations already exist in memory (Barense et al., 2010). However, the present results suggest that unitization can occur for novel objects that are overtly named and repeatedly linked to the same set of pre-existing representations in semantic memory, thereby bypassing a damaged PRC, as evidenced by D.A.'s eventual successful performance on the Abstract-Unitized condition in Sessions 12 and 13.

Regions that are spared in D.A. but damaged in K.C. include left ACC, ventral frontal cortex, and occipital cortex, and bilateral precuneus and dorsal frontal cortex. The left anterior temporal lobe was damaged in both K.C. and R.F.R., but not in D.A. Although speculative, functional interactions among some or all of these regions may promote unitization. The retrieval of existing (semantic) representations may be mediated by left anterior temporal lobe and ACC/ventrolateral frontal cortex interactions (Frankland et al., 2004; Noppeney et al., 2007). The creation of a fused image from these representations may be supported by posterior visual cortices and the precuneus (O'Craven and Kanwisher, 2000; Cavanna and Trimble, 2006), and subsequently maintained on-line by a network of prefrontal regions (Moscovitch and Winocur, 2002; Badre et al., 2010). The ACC may gradually reorganize the corticocortical connections to strengthen the fused representation in memory (Frankland and Bontempi, 2005). R.F.R.'s extensive bilateral anterior temporal lobe damage may have disrupted access to semantic representations (indeed, he has shown mild conceptual knowledge impairments; Barense et al., 2012), and damage to dorsolateral prefrontal cortex in K.C. 
may have disrupted the on-line maintenance of relations during unitization.

Visual imagery, on-line maintenance, and access to semantic memory may each be critical factors in determining whether a patient benefits from unitization. Semantic memory is comparable to that of controls for D.A. (Westmacott and Moscovitch, 2002) and K.C. (Tulving et al., 1991; Westmacott and Moscovitch, 2001), and is mildly impaired in R.F.R. (Barense et al., 2012). D.A.'s and K.C.'s visual imagery is similar to that of controls (Rosenbaum et al., 2004); R.F.R.'s visual imagery has not been tested. D.A. has exhibited a high working memory capacity (Rosenbaum et al., 2008); R.F.R. is within the normal range, whereas K.C.'s working memory capacity is lower, although in the normal range. Differences in working memory/on-line maintenance may set apart the performance of D.A. from those of K.C. and R.F.R. The present work stresses the importance of selecting or tailoring memory rehabilitation strategies to the unique pattern of impaired/spared abilities that have been identified for each patient. Here, findings from D.A. indicate that, in certain cases of amnesia, memory performance may be mediated in the absence of a functioning hippocampus through unitization.

\section{References}

Adlam AL, Patterson K, Bozeat S, Hodges JR (2010) The Cambridge semantic memory test battery: detection of semantic deficits in semantic dementia and Alzheimer's disease. Neurocase 16:193-207. CrossRef Medline

Alvarado MC, Bachevalier J (2005) Selective neurotoxic damage to the hippocampal formation impairs performance of the transverse patterning and location memory tasks in rhesus macaques. Hippocampus 15:118131. CrossRef Medline

Alvarado MC, Rudy JW (1995) Rats with damage to the hippocampalformation are impaired on the transverse-patterning problem but not on elemental discriminations. Behav Neurosci 109:204-211. CrossRef Medline

Badre D, Kayser AS, D’Esposito M (2010) Frontal cortex and the discovery of abstract action rules. Neuron 66:315-326. CrossRef Medline

Barense MD, Bussey TJ, Lee AC, Rogers TT, Davies RR, Saksida LM, Murray EA, Graham KS (2005) Functional specialization in the human medial temporal lobe. J Neurosci 25:10239-10246. CrossRef Medline

Barense MD, Gaffan D, Graham KS (2007) The human medial temporal lobe processes online representations of complex objects. Neuropsychologia 45:2963-2974. CrossRef Medline

Barense MD, Rogers TT, Bussey TJ, Saksida LM, Graham KS (2010) Influence of conceptual knowledge on visual object discrimination: insights from semantic dementia and MTL amnesia. Cereb Cortex 20:2568-2582. CrossRef Medline

Barense MD, Groen II, Lee AC, Yeung LK, Brady SM, Gregori M, Kapur N, Bussey TJ, Saksida LM, Henson RN (2012) Intact memory for irrelevant information impairs perception in amnesia. Neuron 75:157-167. CrossRef Medline

Blumenfeld RS, Parks CM, Yonelinas AP, Ranganath C (2011) Putting the pieces together: the role of the dorsolateral prefrontal cortex in relational memory encoding. J Cogn Neurosci 23:257-265. CrossRef Medline

Brasted PJ, Bussey TJ, Murray EA, Wise SP (2003) Role of the hippocampal system in associative learning beyond the spatial domain. Brain 126:12021223. CrossRef Medline

Bussey TJ, Saksida LM (2005) Object memory and perception in the medial temporal lobe: an alternative approach. Curr Opin Neurobiol 15:730-737. CrossRef Medline

Bussey TJ, Saksida LM (2007) Memory, perception and the visualperirhinal-hippocampal stream: thinking outside of the boxes. Hippocampus 17:898-908. CrossRef Medline

Bussey TJ, Clea Warburton E, Aggleton JP, Muir JL (1998) Fornix lesions can facilitate acquisition of the transverse patterning task: a challenge for "configural" theories of hippocampal function. J Neurosci 18:1622-1631. Medline

Callen DJ, Black SE, Gao F, Caldwell CB, Szalai JP (2001) Beyond the hip- pocampus: MRI volumetry confirms widespread limbic atrophy in AD. Neurology 57:1669-1674. CrossRef Medline

Cavanna AE, Trimble MR (2006) The precuneus: a review of its functional anatomy and behavioural correlates. Brain 129:564-583. CrossRef Medline

Cohen NJ, Eichenbaum H. (1993) Memory, amnesia, and the hippocampal system. Cambridge, MA: MIT.

Cohen NJ, Poldrack RA, Eichenbaum H (1997) Memory for items and memory for relations in the procedural/declarative memory framework. Memory 5:131-178. CrossRef Medline

Corkin S (2002) What's new with the amnesic patient H.M.? Nat Rev Neurosci 3:153-160. CrossRef Medline

Dewar BK, Patterson K, Wilson BA, Graham KS (2009) Re-acquisition of person knowledge in semantic memory disorders. Neuropsychol Rehabil 19:383-421. CrossRef Medline

Driscoll I, Hamilton DA, Petropoulos H, Yeo RA, Brooks WM, Baumgartner RN, Sutherland RJ (2003) The aging hippocampus: cognitive, biochemical and structural findings. Cereb Cortex 13:1344-1351. CrossRef Medline

Driscoll I, Howard SR, Prusky GT, Rudy JW, Sutherland RJ (2005) Seahorse wins all races: hippocampus participates in both linear and non-linear visual discrimination learning. Behav Brain Res 164:29-35. CrossRef Medline

Dusek JA, Eichenbaum H (1998) The hippocampus and transverse patterning guided by olfactory cues. Behav Neurosci 112:762-771. CrossRef Medline

Eichenbaum H, Otto T, Cohen NJ (1994) Two functional components of the hippocampal memory system. Behav Brain Sci 17:449-517. CrossRef

Eichenbaum H, Cohen NJ (2001) From conditioning to conscious recollection: memory systems of the brain. New York: Oxford UP.

Frankland PW, Bontempi B (2005) The organization of recent and remote memories. Nat Rev Neurosci 6:119-130. CrossRef Medline

Frankland PW, Bontempi B, Talton LE, Kaczmarek L, Silva AJ (2004) The involvement of the anterior cingulated cortex in remote contextual fear memory. Science 304:881-883. CrossRef Medline

Glisky EL, Schacter DL, Tulving E (1986) Learning and retention of computer-related vocabulary in memory-impaired patients: method of vanishing cues. J Clin Exp Neuropsychol 8:292-312. CrossRef Medline

Goshen-Gottstein Y, Moscovitch M, Melo B (2000) Intact implicit memory for newly formed verbal associations in amnesic patients following single study trials. Neuropsychologia 14:570-580. CrossRef

Graf P, Schacter DL (1989) Unitization and grouping mediate dissociations in memory for new associations. J Exp Psychol Learn Mem Cogn 15:930 940. CrossRef

Hayman CA, Macdonald CA, Tulving E (1993) The role of repetition and associative interference in new semantic learning in amnesia. J Cogn Neurosci 5:375-389.

Henke K (2010) A model for memory systems based on processing modes rather than consciousness. Nat Rev Neurosci 11:523-532. CrossRef Medline

Insausti $\mathrm{R}$, Juottonen $\mathrm{K}$, Soininen $\mathrm{H}$, Insausti $\mathrm{AM}$, Partanen $\mathrm{K}$, Vainio $\mathrm{P}$, Laakso MP, Pitkänen A (1998) MR volumetric analysis of the human entorhinal, perirhinal and temporopolar cortices. AJNR Am J Neuroradiol 19:659-671. Medline

Knowlton BJ, Morrison RG, Hummel JE, Holyoak KJ (2012) A neurocomputational system for relational reasoning. Trends Cogn Sci 16:373-381. CrossRef Medline

Lee AC, Yeung LK, Barense MD (2012) The hippocampus and visual perception. Front Hum Neurosci 6:91. CrossRef Medline

Moscovitch M, Winocur G (2002) The frontal cortex and working with memory. In: The frontal lobes (Stuss DT, Knight RT, eds), pp 188-209. Oxford, UK: Oxford UP.

Moses SN, Ryan JD (2006) A comparison and evaluation of the predictions of relational and conjunctive accounts of hippocampal function. Hippocampus 16:43-65. CrossRef Medline

Moses SN, Villate C, Ryan JD (2006) An investigation of learning strategy supporting transitive inference performance in humans. Neuropsychologia 44:1370-1387. CrossRef Medline

Moses SN, Ostreicher ML, Rosenbaum RS, Ryan JD (2008) Successful transverse patterning in amnesia using semantic knowledge. Hippocampus 18:121-124. CrossRef Medline

Noppeney U, Patterson K, Tyler LK, Moss H, Stamatakis EA, Bright P, Mum- 
mery C, Price CJ (2007) Temporal lobe lesions and semantic impairment: a comparison of herpes simplex virus encephalitis and semantic dementia. Brain 130:1138-1147. CrossRef Medline

O'Craven KM, Kanwisher N (2000) Mental imagery of faces and places activates corresponding stiimulus-specific brain regions. J Cogn Neurosci 12:1013-1023. CrossRef Medline

Olsen RK, Moses SN, Riggs L, Ryan JD (2012) The hippocampus supports multiple cognitive processes through relational binding and comparison. Front Hum Neurosci 6:146. CrossRef Medline

Olson IR, Moore KS, Stark M, Chatterjee A (2006) Visual working memory is impaired when the medial temporal lobe is damaged. J Cogn Neurosci 18:1087-1097. CrossRef Medline

Quamme JR, Yonelinas AP, Norman KA (2007) Effect of unitization on associative recognition in amnesia. Hippocampus 17:192-200. CrossRef Medline

Reed JM, Squire LR (1999) Impaired transverse patterning in human amnesia is a special case of impaired memory for two-choice discrimination tasks. Behav Neurosci 113:3-9. CrossRef Medline

Rickard TC, Grafman J (1998) Losing their configural mind: amnesic patients fail on transverse patterning. J Cogn Neurosci 10:509-524. CrossRef Medline

Rickard TC, Verfaellie M, Grafman J (2006) Transverse patterning and human amnesia. J Cogn Neurosci 18:1723-1733. CrossRef Medline

Rosenbaum RS, McKinnon MC, Levine B, Moscovitch M (2004) Visual imagery deficits, impaired strategic retrieval, or memory loss: disentangling the nature of an amnesic patient's autobiographical memory deficit. Neuropsychologia 42:1619-1635. CrossRef Medline

Rosenbaum RS, Köhler S, Schacter DL, Moscovitch M, Westmacott R, Black SE, Gao F, Tulving E (2005) The case of K.C.: contributions of a memory-impaired person to memory theory. Neuropsychologia 43:9891021. CrossRef Medline

Rosenbaum RS, Moscovitch M, Foster JK, Schnyer DM, Gao F, Kovacevic N, Verfaellie M, Black SE, Levine B (2008) Patterns of autobiographical memory loss in medial-temporal lobe amnesic patients. J Cogn Neurosci 20:1490-1506. CrossRef Medline

Rosenbaum RS, Gilboa A, Levine B, Winocur G, Moscovitch M (2009) Amnesia as an impairment of detail generation and binding: evidence from personal, fictional, and semantic narratives in K.C. Neuropsychologia 47:2181-2187. CrossRef Medline
Saksida LM, Bussey TJ, Buckmaster CA, Murray EA (2007) Impairment and facilitation of transverse patterning after lesions of the perirhinal cortex and hippocampus, respectively. Cereb Cortex 17:108-115. Medline

Sutherland RJ, Rudy JW (1989) Configural association theory: the role of the hippocampal-formation in learning, memory, and amnesia. Psychobiology 17:129-144.

Tulving E (1985) Memory and consciousness. Can Psychol 26:1-12. CrossRef

Tulving E, Patterson RD (1968) Functional units and retrieval processes in free recall. J Exp Psychol 77:239-248. CrossRef Medline

Tulving E, Hayman CA, Macdonald CA (1991) Long-lasting perceptual and semantic learning in amnesia: a case experiment. J Exp Psychol Learn Mem Cogn 17:595-617. CrossRef Medline

Verfaelllie M, LaRocque KF, Keane MM (2012) Intact implicit verbal relational memory in MTL amnesia. Neuropsychologia 50:2100-2106. CrossRef Medline

Warrington EK, McCarthy RA (1988) The fractionation of retrograde amnesia. Brain Cogn 7:184-200. CrossRef Medline

Wendelken C, Bunge SA (2010) Transitive inference: distinct contributions of rostrolateral prefrontal cortex and the hippocampus. J Cogn Neurosci 22:837-847. CrossRef Medline

Westmacott R, Moscovitch M (2001) Names and words without meaning: incidental post-morbid semantic learning in a person with extensive bilateral hippocampal damage. Neuropsychology 15:586-596. CrossRef Medline

Westmacott R, Moscovitch M (2002) Temporally-graded retrograde memory loss for famous names and vocabulary terms in amnesia and semantic dementia: further evidence for opposite gradients using implicit memory tests. Cogn Neuropsychol 19:135-163. CrossRef Medline

Wickelgren WA (1968) Sparing of short-term memory in an amnestic patient: implications for strength theory of memory. Neuropsychologia 6:235-244. CrossRef

Winocur G (1992) A comparison of normal old rats and young adult rats with lesions to the hippocampus or prefrontal cortex on a test of matching-to-sample. Neuropsychologia 30:769-781. CrossRef Medline

Winograd E, Rivers-Bulkeley NT (1977) Effects of changing context on remembering faces. J Exp Psychol Hum Learn Mem 4:397-405. 